\title{
AVALIAÇÃO ANTIBACTERIANA DO EXTRATO AQUOSO DA FOLHA DE Caryocar brasiliense CAMBESS. (CARYOCARACEAE).
}

\section{ANTIBACTERIAL EVALUATION OF LEAF AQUEOUS EXTRACT OF Caryocar brasiliense CAMBESS. (CARYOCARACEAE).}

\section{Débora da Silva MACHADO'; Samuel Geraldo Ferreira de ABREU1'; Ludmila Oliveira LAMOUNIER $^{2}$; Daniel NEGREIROS ${ }^{1 *}$}

1 - Instituto de Ciências Biológicas e Saúde, Centro Universitário UNA, Belo Horizonte, MG, Brasil.

2 - Fundação Ezequiel Dias (FUNED), Belo Horizonte, MG, Brasil.

* Autor para correspondência: E-mail: negreiros.eco@gmail.com

\section{RESUMO:}

A utilização da fitoterapia é comum desde os primórdios da humanidade. Pesquisadores se ocupam com pesquisas voltadas para o rastreamento fitoquímico de vegetais utilizados pela medicina fitoterápica. O presente trabalho foi realizado com o objetivo de avaliar o potencial antibacteriano do extrato aquoso da folha de Caryocar brasiliense frente aos microrganismos Enterococcus faecalis, Escherichia coli, Staphylococcus aureus e Pseudomonas aeruginosa. Foram realizados testes com disco de difusão em ágar, logo após aferido o halo e comparado com padrões estabelecidos. O extrato aquoso da folha do C. brasiliense apresentou bioatividade inibitória somente sobre a bactéria $S$. aureus em concentração de $50 \mathrm{~g} / \mathrm{mL}$, não demonstrando atividade sobre as demais bactérias, $E$. coli, $E$. faecalis e $P$. aeruginosa. A inibição provocada no crescimento de $S$. aureus foi classificada como uma inibição intermediária (i.e., halo maior que $12,5 \mathrm{~mm}$ e menor que $17,5 \mathrm{~mm} ; p<0,001)$.

Palavras-chave: Antibacteriano, Enterococcus faecalis, Escherichia coli, Fitoterapia, Pequi, Pseudomonas aeruginosa, Staphylococcus aureus.

\begin{abstract}
:
The use of herbal medicine is common since the beginnings of mankind. Researchers are engaged in research aimed at the phytochemical screening of plants used by herbal medicine. The present work was carried out with the objective of evaluating the antibacterial potential of the aqueous extract of Caryocar brasiliense leaf against the microorganisms Enterococcus faecalis, Escherichia coli, Staphylococcus aureus and Pseudomonas aeruginosa. A diffusion disc test was performed on agar, after measuring the halo and compared with established standards. The aqueous extract of the $C$. brasiliense leaf presented inhibitory bioactivity only on the $S$. aureus bacterium at a concentration of 50 $\mathrm{g} / \mathrm{mL}$, showing no activity on the other bacteria, $E$. coli, E. faecalis and $P$. aeruginosa. The inhibition induced on $S$. aureus growth was classified as an intermediate inhibition (i.e., halo greater than $12.5 \mathrm{~mm}$ and less than $17.5 \mathrm{~mm} ; p<0.001$ ).
\end{abstract}

Key words: Phytotherapy, Pequi, Antibacterial, Enterococcus faecalis, Escherichia coli, Pseudomonas aeruginosa, Staphylococcus aureus. 


\section{INTRODUÇÃO}

Desde os primórdios da civilização a humanidade utiliza determinadas plantas para combater suas enfermidades como uma das principais formas de inibir a evolução das doenças (RODRIGUEZ, 2008). A botânica, a farmacologia e a fitoquímica são as ciências envolvidas na pesquisa de fitoterápicos e responsáveis pelos fundamentos teóricos e testes científicos relativos ao uso das plantas medicinais na cultura popular (ARNOUS; SANTOS; BEINNER, 2005). Na década de 1990, 65 a $80 \%$ da população de países emergentes dependiam do uso de espécimes vegetais no combate, controle ou prevenção de doenças, pelo fato de ser um recurso acessível a essa população (VEIGA JUNIOR; PINTO; MACIEL, 2005). Tratamentos alternativos para o controle bacteriano foram intensificados nos últimos anos, tendo em vista a capacidade que os antibióticos de origem vegetal possuem de ativar ou bloquear reações e síntese enzimática de patógenos (MICHELIN et al., 2005; PUPO et al., 2007; PINHO et al., 2012). Estes antibióticos de origem vegetal podem ser utilizados para combater disfunções como: doenças do trato digestivo ou intestinal, do sistema respiratório entre outras (MEDEIROS; FONSECA; ANDREATA, 2004; VARANDA, 2009; MILLEZI et al., 2013; ROCHA et al., 2014; CARNEIRO et al., 2015).

O Caryocar brasiliense (Caryocaraceae), conhecido como pequi, é uma espécie arbórea cuja infusão de suas folhas pode estimular a produção de bílis, além de ser usada para disfunções hepáticas, regulação de fluxo menstrual, além de possuir função adstringente (PAULA JUNIOR, 2004; ARRUDA; CRUZ; ALMEIDA, 2012). As folhas de $C$. brasiliense apresentam compostos fenólicos, taninos e óleos essenciais que possuem ação antioxidante, auxiliando no combate da ação oxidativa dos radicais livres, além de possuir ação antibacteriana (RIBEIRO, 2000; PAULA JUNIOR, 2004; LIMA et al., 2007; FIGUEIRA, 2014). Esses compostos em conjunto despertam um alto interesse farmacológico, visto que conferem ao seu extrato bioatividade contra agentes patogênicos (CARVALHO; PEREIRA; ARAÚJO, 2015). Estes compostos podem ser isolados e aplicados na indústria farmoquímica, de cosméticos, alimentícia, sendo que seu uso seria viável na produção de novos fármacos pela considerável atividade biológica que esses compostos contêm (SILVA, 2013).

Diversos estudos exploraram a atuação de compostos presentes em plantas capazes de desencadear respostas em microrganismos ou células (OSTROSKY et al., 2008; ALVES, 2014; DE SOUZA et al., 2015). Com o decorrer dos anos os microrganismos patogênicos estão desenvolvendo linhagens resistentes a fármacos normalmente utilizados 
para combater a proliferação dos mesmos em pacientes debilitados (OLIVEIRA; KOVNER; SILVA, 2010). Por exemplo, a bactéria Enterococcus faecalis tem sido um importante patógeno capaz de evadir a ação farmacológica de medicamentos administrados em hospitais (TAVARES, 2000; RUIZ-GARBAJOSA et al., 2006). Esta bactéria é frequentemente encontrada no sistema digestivo de pessoas saudáveis, além da cavidade bucal e da vagina (SUNDQVIST, 1992), possuindo um comportamento oportunista, grande capacidade de resistência e prejudicando a homeostase do organismo hospedeiro, o que pode levar o mesmo até ao óbito (TAVARES, 2000). A patogenicidade pode se dar quando o E. faecalis atravessa as mucosas que foram comprometidas de alguma forma, se alojando nos tecidos, provocando lesões locais e liberando toxinas, além de apresentarem resistência a antibióticos (D'AZEVEDO; DIAS; TEIXEIRA, 2006; GAMA, 2008).

A bactéria Staphylococcus aureus é capaz de causar diversas enfermidades nos humanos desde que seu sistema imunológico esteja debilitado, causando assim disfunções, caso não seja tratada precocemente (VIEGAS et al., 2010). Pode possuir vários meios de evasão do sistema de defesa no ser vivo (GELATTI et al., 2009). Apresenta em seus genes codificadores a capacidade de sintetizar proteínas, como a exotoxina denominada leucocidina de Panton-Valentine, que atua de forma necrotizante sobre os tecidos causando também destruição dos leucócitos por intermédio da abertura de fissuras na membrana celular, causando a lise protoplásmica, que pode levar ao estado clínico mais avançado associado a infecções cutâneas, como furúnculos (GELATTI et al. 2009). A resistência de $S$. aureus a antibióticos é proveniente de mutações em seus genes ou mesmo adquiridas de genes resistentes de outras bactérias (SANTOS et al., 2007).

O microrganismo Escherichia coli, residente da microbiota endógena dos humanos (PELCZAR; REID; CHAN, 1981), é fonte de diversas linhagens que possuem resistência e são patogênicas para organismos hospedeiros, devido a fatores como mutação espontânea (SIQUEIRA et al., 2008) e recombinação de genes presentes em plasmídeos que carregam sequências codificadoras de resistência a drogas que podem ser transferidos entre amostras diferentes ou ainda em mutações cromossômicas (VAZ, 2009). Tais fatores contribuem para uma maior variabilidade genética entre as bactérias, proporcionando a essas maiores vantagens adaptativas (BRITO et al., 2004; MOTA et al. 2005).

O microrganismo Pseudomonas aeruginosa pode causar diversas enfermidades em pacientes já debilitados (FUENTEFRIA et al., 2008), sendo responsável por desencadear quadros clínicos como a pneumonia, infecções nosocomiais graves por ser um microrganismo muito presente em ambientes hospitalares (GALES; REIS; JONES, 
2001; FIGUEIREDO et al., 2007). Além disso, $P$. aeruginosa é capaz de desenvolver linhagens multirresistentes a antibióticos que normalmente seriam capazes de realizar seu controle (GALES; REIS; JONES, 2001). A virulência se dá por diversas propriedades, tais como a capacidade de: i) aderir e mudar a fisiologia das células hospedeiras (FERRAREZE et al., 2007); ii) invadir tecidos, apresentar resistência a antibióticos e capacidade de produção de toxinas (DA MATA; ABEGG, 2013); iii) sintetizar enzimas com alto poder de destruição de membranas celulares, como a fosfolipase C e $\beta$-lactamases (MASUDA; OHYA, 1992); e iv) inativar opsoninas, debilitando a resposta efetora do sistema imunológico do paciente (PELCZAR; REID; CHAN, 1981; GONÇALVES et al., 2009).

O presente trabalho foi realizado com o objetivo de avaliar o potencial antibacteriano do extrato aquoso da folha de Caryocar brasiliense frente aos microrganismos E. faecalis, E. coli, S. aureus e $P$. aeruginosa.

\section{MATERIAL E MÉTODOS}

As folhas de $C$. brasiliense manipuladas para compor o extrato foram coletadas em São José, distrito de Esmeraldas, MG (localizado a 25 km do centro do município). Após a coleta, as folhas foram armazenadas em potes opacos de polietileno e mantidas congeladas a $-6^{\circ} \mathrm{C}$ até o processamento da extração. A produção do extrato aquoso da folha foi realizada no Laboratório de Botânica do ICBS, Centro Universitário UNA (Campus Guajajaras), Belo Horizonte, MG. Foi utilizado um tubo Falcon de $50 \mathrm{~mL}$, contendo folhas inteiras do $C$. brasiliense desidratada em estufa a temperatura de $25^{\circ} \mathrm{C}$, que posteriormente foram trituradas. $\mathrm{O}$ extrato foi solubilizado em água purificada estéril na concentração de $50 \mathrm{~g} / \mathrm{mL}$ (50\%) para a extração dos compostos da folha de C. brasiliense. Todos os procedimentos foram realizados de acordo com Müller (2006), Alvarenga e colaboradores (2007) e Pinho e colaboradores (2012).

A solução obtida foi homogeneizada mecanicamente e o tubo etiquetado, envolvido com papel alumínio e armazenado em local escuro para repouso por sete dias. Este tempo foi necessário para que a água extraísse os compostos químicos da planta. Após este

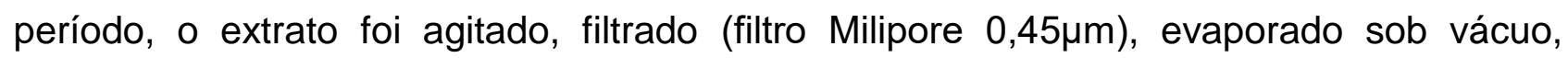
conforme Pessini e colaboradores (2003). Em seguida, o material foi ressuspendido em 50 $\mathrm{mL}$ de água purificada estéril com o objetivo de retirar quaisquer microrganismos que poderiam interferir no resultado do experimento, conforme Fernandes; dos Santos; Pimenta (2007). 
Os microrganismos, Staphylococcus aureus (ATCC25923), Escherichia coli (ATCC25922), Enterococcus faecalis (ATCC29212) e Pseudomonas aeruginosa (ATCC27853) foram obtidos na Divisão de Higienização e Produção de Meios de Cultura (DHPMC) da Fundação Ezequiel Dias (FUNED), em Belo Horizonte, MG. As bactérias foram cultivadas em Blood Agar Base (Ágar Sangue) durante um período de 24 horas e posteriormente foram diluídas em $2 \mathrm{~mL}$ de salina na concentração de $1,5 \times 10^{8}$ unidades formadoras de colônias (UFC) que corresponde a 0,5 da escala de McFarland (LOGUERCIO et al., 2005).

Para o plaqueamento, para cada $1000 \mathrm{ml}$ de água purificada foram preparados $38 \mathrm{~g}$ de meio de cultura Mueller Hinton Difco (POLETTO; REIS, 2005). O meio foi autoclavado e distribuído em placas de Petri estéreis. Após este processo, foi realizado o plaqueamento por estrias das bactérias em todo o meio, utilizando um swab. Delimitou-se o espaço para aplicação do disco de difusão impregnados com extrato de $C$. brasiliense, sendo utilizados $20 \mu \mathrm{L}$ do extrato já ressuspendido com o auxílio de uma pipeta automática, conforme Michelin et al. (2005). Logo após esta etapa, os discos de difusão foram fixados ao meio e as placas foram incubadas em estufa bacteriológica por 24 horas a $37^{\circ} \mathrm{C}$ (BARA; VANETTI, 1998; NCCLS, 2003; PEREIRA et al., 2006; ALVES et al., 2008). Após esta etapa as placas foram analisadas em relação ao tamanho do halo de inibição, medindo-os com paquímetro analógico (precisão 1mm) (LABORCLIN, 2011).

Foi utilizado um delineamento experimental fatorial, com dois fatores: (1) Espécie de microrganismo (4 níveis: S. aureus, E. coli, E. faecalis e $P$. aeruginosa); e (2) presença de extrato de $C$. brasiliense (2 níveis: com extrato aquoso de $C$. brasiliense, e com antibiótico específico) (LABORCLIN, 2011). Cada placa teve uma pseudo-réplica de disco de difusão. $\mathrm{A}$ unidade experimental considerada foi à placa, e foram feitas 10 repetições para cada tratamento. Adicionalmente foi realizado tratamento sem o extrato para servir de controle negativo, e com este fim foram utilizadas dez placas com um disco de difusão impregnado apenas com água purificada estéril (utilizada pra ressuspender o extrato).

A concentração mínima inibitória (CMI) do extrato foi determinada por diluições seriadas a partir do extrato bruto conforme Ostrosky et al. (2008). Os valores do diâmetro do halo de inibição em cada tratamento foram comparados com os valores de referência que classificam os microrganismos como Resistente, Intermediário e Sensível (ANVISA, 2003; LABORCLIN, 2011). Estas comparações foram feitas com o uso do Teste-T para uma amostra (QUINN; KEOUGH, 2002), considerando o nível de significância $(\alpha=0,05)$. 


\section{RESULTADOS E DISCUSSÃO}

O presente estudo demonstrou que o extrato aquoso da folha de $C$. brasiliense testado sobre as quatro linhagens distintas de microrganismos (S. aureus, E. faecalis, $E$. coli e $P$. aeruginosa) apresentou atividade inibitória apenas sobre a $S$. aureus. A inibição provocada no crescimento de $S$. aureus foi classificada como uma inibição intermediária (i.e., halo maior que $12,5 \mathrm{~mm}$ e menor que $17,5 \mathrm{~mm} ; p<0,001$ ), quando comparado o diâmetro do halo formado com padrões pré-estabelecidos por órgãos competentes, como a Agência Nacional de Vigilância Sanitária (LABORCLIN, 2011). Portanto a concentração mínima inibitória $(\mathrm{CMI})$ foi atingida somente para $S$. aureus, sendo eficaz até a concentração de $10^{-3}$ (Figura 1).

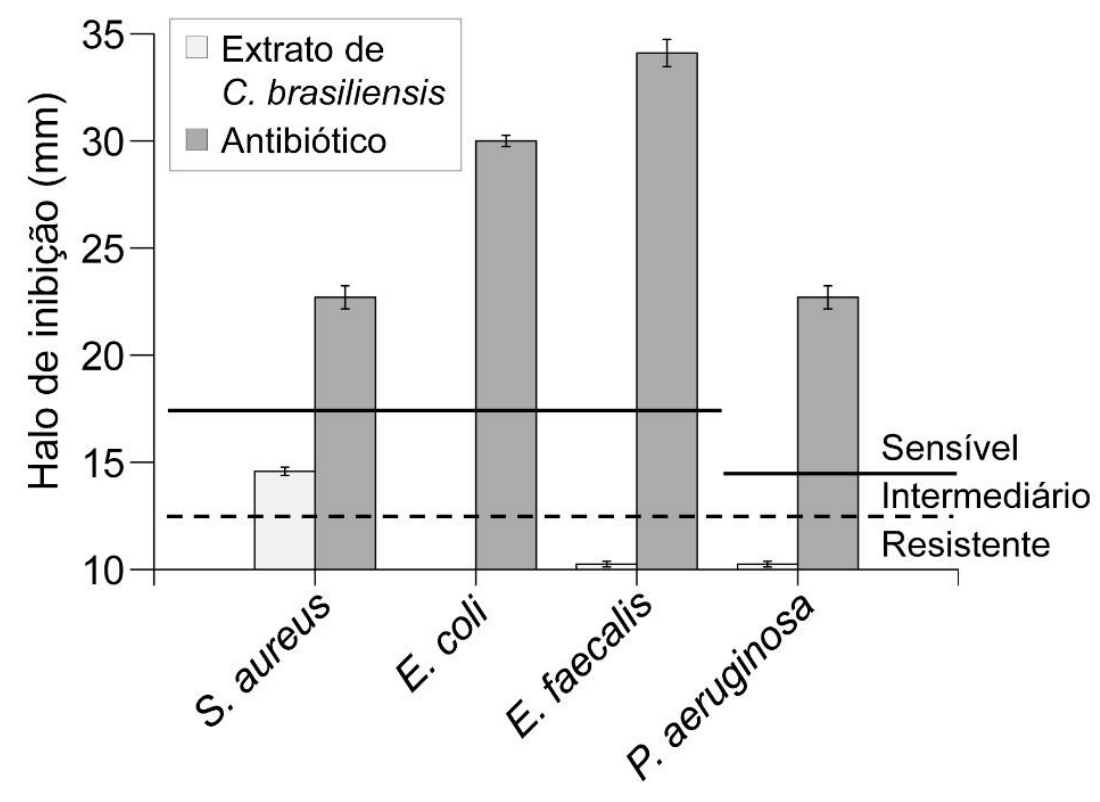

FIGURA 1. Atividade inibitória do crescimento de quatro bactérias pelo extrato aquoso (concentração de $50 \%$ ) da folha de $C$. brasiliense (Caryocaraceae). $O$ antibiótico específico utilizado correspondeu ao Cloranfenicol para S. aureus, E. coli e E. faecalis, e Gentamicina para $P$. aeruginosa.

Os discos de difusão impregnados com o extrato aquoso de $C$. brasiliense sobre as placas com as bactérias $E$. faecalis, E. coli e $P$. aeruginosa não foram capazes de formar o halo, indicando assim a ausência de atividade inibitória ( $p>0,05$; Figura 1).

Os resultados demonstrados no presente trabalho divergem do que foi encontrado por Pinho e colaboradores (2012), sendo que o extrato hidroalcoólico da casca do fruto do C. brasiliense não apresentou atividade inibitória sobre o crescimento de $S$. aureus em 
concentrações de 200 a $500 \mathrm{mg} / \mathrm{mL}^{-1}$. É possível observar através de rastreamento fitoquímico que $C$. brasiliense possui metabolitos com possível atividade bacteriostática, como as catequinas, esteroides, saponinas, taninos, xantonas entre outras.

Em estudos realizados por Fonseca e colaboradores (2014) o extrato aquoso das folhas e da casca de C. brasiliense a $100 \mathrm{mg} / \mathrm{mL}$ apresentaram $91,3 \%$ de eficácia, interferindo contra o desenvolvimento larval de nematódeos que são capazes de desencadear enfermidades em bovinos, prejudicando na eclodibilidade dos helmintos. Nesse mesmo estudo, os autores indicaram que compostos secundários produzidos por $C$. brasiliense são capazes realizarem atividade anti-helmíntica, além de possuírem outras funções. Segundo Lopes e colaboradores (2011), o extrato hidroalcoólico da folha de $C$. brasiliense possui atividade moluscicida sobre Biomphalaria glabrata, hospedeiro intermediário do Schistosoma mansoni, e análises cromatográficas indicaram altas concentrações de esteróides, que são compostos bioativos sintetizados pelo C. brasiliense.

O estudo de Paula Junior (2004) coincide parcialmente com os resultados reportados no presente estudo, pois este autor utilizou extratos hidroetanólicos da folha e do mesocarpo interno de $C$. brasiliense, tendo observado uma baixa atividade inibitória sobre as bactérias: E. coli (ATCC25922), S. aureus (ATCC25923), E. faecalis (ATCC29212) e $P$. aeruginosa (ATCC27853), embora somente o extrato da folha apresentou resultados efetivos sobre os microrganismos, variando de acordo com a concentração do extrato (1; 1,5 e $2 \mathrm{mg} / \mathrm{mL}$ ). O mesmo autor também avaliou a atividade do extrato hidroetanólico da folha de $C$. brasiliense sobre culturas de formas promastigotas de Leishimania amanzonensis in vitro em concentrações de 2,5 e $5 \mathrm{mg} / \mathrm{mL}$, encontrando uma possível atividade antileishmanicida. Outros estudos, como o de Ono e colaboradores (1990), indicam que os compostos fenólicos presentes no $C$. brasiliense teriam a capacidade de reagir com enzimas essenciais para a vida de alguns organismos, como a realização de interações com transcriptases reversas de vírus e por fim inibindo a sua ação, consequentemente cessando a replicação viral.

Diversos estudos buscam investigar os compostos que poderiam impedir e impossibilitar a proliferação de organismos infecciosos. Estudos realizados por Passos e colaboradores $(2002,2003)$ demonstraram possíveis ações antifúngicas do extrato bruto etanólico da folha de $C$. brasiliense frente à Cryptococcus neoformans em uma concentração $\leq 1.000 \mu \mathrm{g} / \mathrm{mL}$. Além disso, Miguel (2011) mostrou que o extrato etanólico da casca de $C$. brasiliense possui capacidade neuroprotetora em doses de 300 e $600 \mathrm{mg} / \mathrm{kg}$, após indução de isquemia que desencadeavam distúrbios cerebrais em ratos. Nesse 
mesmo estudo, o autor verificou a diminuição de neurônios isquêmicos que são indicativos de necrose isquêmica.

A ausência de resposta efetiva inibitória do extrato aquoso da folha de $C$. brasiliense sobre as culturas de bactérias $E$. faecalis, $E$. coli e $P$. aeruginosa pode ter sido decorrente de fatores como a concentração do extrato em questão, qualidade da parte vegetal utilizada, variação da disponibilidade de nutrientes no solo, teor de compostos bioativos, pluviometria, sazonalidade entre outros. Estes fatores poderiam explicar o motivo de outros estudos terem chegado a resultados distintos, mesmo utilizando a mesma espécie para testes (PINHO et al., 2012).

\section{AGRADECIMENTOS}

Agradecemos a F. F. Souza e J. S. Miranda pela revisão crítica nas versões iniciais do manuscrito, e a Fundação Ezequiel Dias (FUNED) pelo apoio logísitico.

\section{REFERÊNCIAS}

ALVES, E. G.; VINHOLIS, A. H. C.; CASEMIRO, L. A.; FURTADO, N. A. J. C.; SILVA, M. L. A.; CUNHA, W. R.; MARTINS, C. H. G. Estudo comparativo de técnicas de screening para avaliação da atividade antibacteriana de extratos brutos de espécies vegetais e de substâncias puras. Química Nova, v. 31, n. 5, p. 1224-1229, 2008.

ALVES, A. I. Obtenção de extrato de carotenoides de polpa de pequi (Caryocar brasiliense Camb.) encapsulado pelo método de secagem por atomização. Viçosa, 95 p. Dissertação (Mestrado). Universidade Federal de Viçosa, Programa de Pós-Graduação em Ciência e Tecnologia de Alimentos. 2014.

ALVARENGA, A. L.; SCHWAN, R. F.; DIAS, D. R.; SCHWAN-ESTRADA, K. R. F.; BRAVOMARTINS, C. E. C. Atividade antimicrobiana de extratos vegetais sobre bactérias patogênicas humanas. Revista Brasileira de Plantas Medicinais, v. 9, n. 4, p. 86-91, 2007.

ANVISA. Agência Nacional de Vigilância Sanitária. Padronização dos Testes de Sensibilidade a Antimicrobianos por Disco-difusão: Norma Aprovada- Oitava Edição. M2-A8. Vol. 23 No 1. Substitui a Norma M2-A7. Vol. 20 No. 1. 2003. 
ARNOUS, A. H.; SANTOS, A. S.; BEINNER, R. P. C. Plantas medicinais de uso caseiroconhecimento popular e interesse por cultivo comunitário. Revista Espaço para a Saúde, v. 6, n. 2, p. 1-6, 2005.

ARRUDA, H. S.; CRUZ, R. G.; ALMEIDA, M. E. F. Caracterização química, funcionalidade e toxicidade do pequi. Nutrição Brasil. Rio Parnaíba, 2012.

BARA, M. T. F.; VANETTI, M. C. D. Estudo da atividade antibacteriana de plantas medicinais, aromáticas e corantes naturais. Revista Brasileira de Farmacognosia, v. 7-8, n. 1, p. 22-34, 1998.

BRITO, B. G.; VIDOTTO, M. C.; BERBEL, M. M.; TAGLIARI, K. C. Fatores de virulência presentes em amostras de Escherichia coli uropatogênicas- UPEC para suínos. Ciência Rural, v. 34, n. 2, 2004.

CARNEIRO, F. M.; SILVA, M. J. P. D.; BORGES, L. L.; ALBERNAZ, L. C.; COSTA, J. D. P. Tendências dos estudos com plantas medicinais no Brasil. Revista Sapiência: sociedade, saberes e práticas educacionais, v. 3, n. 2, p. 44-75, 2015.

CARVALHO, L. S.; PEREIRA, K. F.; ARAÚJO, E. G. Características botânicas, efeitos terapêuticos e princípios ativos presentes no Pequi (Caryocar brasiliense). Arquivo Ciências Saúde UNIPAR, v. 19, n. 2, 2015.

DA MATA, P. T. G.; ABEGG, M. A. Descrição de caso de resistência a antibióticos por Pseudomonas aeruginosa. Arquivos do Museu Dinâmico Interdisciplinar, v. 11, n. 2, p. 20-25, 2013.

D'AZEVEDO, P. A.; DIAS, C. A. G.; TEIXEIRA, L. M. Genetic diversity and antimicrobial resistance of enterococcal isolates from southern region of Brazil. Revista do Instituto de Medicina Tropical de São Paulo, v. 48, n. 1, p. 11-16, 2006.

DE SOUZA, J. C. et al. Avaliação da atividade antibacteriana e modulatória do extrato metanólico da folha de Myracrodruon urundeuva (Anacardiaceae). Acta Biológica Paranaense, v. 44, n. 1-2. 2015. 
FERNANDES, T. T.; DOS SANTOS, A. T. F.; PIMENTA, F. C. Atividade Antimicrobiana das plantas Plathymenia reticulata, Hymenaea courbaril e Guazuma ulmifolia. Revista de Patologia Tropical, v. 34, n. 2, 2007.

FERRAREZE, M. V. G.; LEOPOLDO, V. C.; ANDRADE, D.; SILVA, M. F. I.; HAAS, V. J. Pseudomonas aeruginosa multiresistente em unidade de cuidados intensivos: desafios que procedem?. Acta Paulista de Enfermagem, v. 20, n. 1, p. 7-11, 2007.

FIGUEIRA, F. V. Secagem de pequi (Caryocar brasiliensis Cambess) precedida de desidratação osmótica. 66 p. Dissertação (Mestrado em Engenharia Agrícola) Universidade Federal de Lavras, Lavras, 2014.

FIGUEIREDO, E. A. P.; RAMOS, H.; MACIEL, M. A. V.; VILAR, M. D. C. M.; LOUREIRO, N. G.; PEREIRA, R. G. Pseudomonas aeruginosa: frequência de resistência a múltiplos fármacos e resistência cruzada entre antimicrobianos no Recife/PE. Revista Brasileira de Terapia Intensiva, v. 19, n. 4, p. 421-427, 2007.

FONSECA, L. D. et al. Eficácia in vitro de extratos aquosos de plantas no controle de nematódeos gastrintestinais de bovinos. Acta Scientiae Veterinariae, v. 42, p. 1-8, 2014.

FUENTEFRIA, D. B.; FERREIRA, A. E.; GRÄF, T.; CORÇÃO, G. Pseudomonas aeruginosa: disseminação de resistência antimicrobiana em efluente hospitalar e água superficial. Revista da Sociedade Brasileira de Medicina Tropical, v. 41, n. 5, p. 470-473, 2008.

GALES, A. C.; REIS, A. O.; JONES, R. N. Contemporary assessment of antimicrobial susceptibility testing methods for polymyxin B and colistin: review of available interpretative criteria and quality control guidelines. Journal of Clinical Microbiology, v. 39, n. 1, p. 183-190, 2001.

GAMA, B. A. Análise da resistência antimicrobiana e de genes de virulência de Enterococcus spp. 2008. Tese de Doutorado. Universidade Federal do Rio Grande Do Sul.

GELATTI, L. C. et al. Sepse por Staphylococus aureus resistente à meticilina adquirida na comunidade no sul do Brasil. Revista da Sociedade Brasileira de Medicina Tropical, v. 42, n.4, p. 458-60, 2009. 
GONÇALVES, D. C. P. S.; LIMA, A. B. M.; LEÃO, L. S. N. D. O.; CARMO FILHO, J. R. D.; PIMENTA, F. C.; VIEIRA, J. D. G. Detection of metallo-beta-lactamase in Pseudomonas aeruginosa isolated from hospitalized patients in Goiania, State of Goiás. Revista da Sociedade Brasileira de Medicina Tropical, v. 42, n. 4, p. 411-414, 2009.

LABORCLIN. Manual para Antibiograma, Difusão em Disco (Kirby \& Bauer). Pinhais: LABORCLIN, 2011.

LIMA, A. D.; SILVA, A. M. O.; TRINDADE, R. A.; TORRES, R. P.; MANCINI-FILHO, J. Composição química e compostos bioativos presentes na polpa e na amêndoa do pequi (Caryocar brasiliense, Camb.). Revista Brasileira de Fruticultura, v. 29, n. 3, p. 695-698, 2007.

Loguercio, A. P.; Battistin, A.; De VARGas, A. C.; HenZEL, A.; WitT, N. M. Atividade antibacteriana de extrato hidro-alcoólico de folhas de jambolão (Syzygium cumini (L.) Skells). Ciência Rural, v. 35, n. 2, p. 371-376, 2005.

LOPES, T. C.; GONÇALVES, J. D. R. S.; SOUZA, N. S.; MORAES, D. F. C.; DO AMARAL, F. M. M.; ROSA, I. G. Avaliação moluscicida e perfil fitoquímico das folhas de Caryocar brasiliense CAMB. Cadernos de Pesquisa, v. 18, n. 3, 2011.

MASUDA, N.; OHYA, S. Cross-resistance to meropenem, cephems, and quinolones in Pseudomonas aeruginosa. Antimicrobial Agents and Chemotherapy, v. 36, n. 9, p. 18471851, 1992.

MEDEIROS, M. F. T.; FONSECA, VS da; ANDREATA, R. H. P. Plantas medicinais e seus usos pelos sitiantes da Reserva Rio das Pedras, Mangaratiba, RJ, Brasil. Acta Botanica Brasilica, v. 18, n. 2, p. 391-399, 2004.

MICHELIN, D. C.; MORESCHI, P. E.; LIMA, A. C.; NASCIMENTO, G. G. F.; PAGANELLI, M. O.; CHAUD, M. V. Avaliação da atividade antimicrobiana de extratos vegetais. Revista Brasileira de Farmacognosia, v.15, n.4, p.316-320, 2005.

MIGUEL, M. P. Ação neuroprotetora do extrato etanólico da casca de pequi em cérebros de ratos submetidos à isquemia e reperfusão. 2011. 79 p. Tese de Doutorado, 
Escola de Veterinária e Zootecnia da Universidade Federal de Goiás, UFG - Goiânia.

MILLEZI, A. F.; BAPTISTA, N. N.; CAIXETA, D. S.; ROSSONI, D. F.; CARDOSO, M. G.; PICCOLI, R. H. Essential oil characterization and its antibacterial activity from culinary and medicinal plants against Staphylococcus aureus and Escherichia coli. Revista Brasileira de Plantas Medicinais, v. 15, n. 3, p. 373-379, 2013.

MOTA, R. A.; DA SILVA, K. P. C.; DE FREITAS, M. F. L.; PORTO, W. J. N.; DA SILVA, L. B. G. Utilização indiscriminada de antimicrobianos e sua contribuição a multirresistências bacteriana. Brazilian Journal of Veterinary Research and Animal Science, v. 42, n. 6, p. 465-470, 2005.

MÜLLER, J. B. Avaliação das atividades antimicrobiana, antioxidante e antinociceptiva das folhas da Luehea divaricata Martius. 2006. Tese de Doutorado, Universidade Federal de Santa Maria, Santa Maria.

NCCLS - National Committee for Clinical Laboratory Standard. Methods for dilution antimicrobial susceptibility tests for bacteria that grow aerobically, approved standard - M7-A6, ed 6, vol. 23, 2003.

OLIVEIRA, A. C.; KOVNER, C. T.; SILVA, R. S. Nosocomial infection in an intensive care unit in a Brazilian university hospital. Revista Latino Americana de Enfermagem, v. 18, n. 2, p. 233-239, 2010.

OLIVEIRA, U. et al. The strong influence of collection bias on biodiversity knowledge shortfalls of Brazilian terrestrial biodiversity. Diversity and Distributions, v. 22, n. 12, p. 1232-1244, 2016.

ONO, K.; NAKANE, H.; FUKUSHIMA, M.; CHERMANN, J. C.; BARRÉ-SINOUSSI, F. Differential inhibitory effects of various flavonoids on the activities of reverse transcriptase and cellular DNA and RNA polymerases. European Journal of Biochemistry, v. 190, p. 469-476, 1990.

OSTROSKY, E. A.; MIZUMOTO, M. K.; LIMA, M. E.; KANEKO, T. M.; NISHIKAWA, S. O.; FREITAS, B. R. Métodos para avaliação da atividade antimicrobiana e determinação da 
concentração mínima inibitória $(\mathrm{CMI})$ de plantas medicinais. Revista Brasileira de Farmacognosia, v. 18, n. 2, p. 301-307, 2008.

PASSOS, X. S.; SANTOS, S. D. C.; FERRI, P. H.; FERNANDES, O. D. F. L.; PAULA, T. D. F.; GARCIA, A. C. F.; SILVA, M. D. R. R. Atividade Antifúngica de Caryocar brasiliensis (Caryocaraceae) sobre Cryptococcus neoformans. Revista da Sociedade Brasileira de Medicina Tropical, v. 35, n. 6, p. 623-627, 2002.

PASSOS, X. S. et al. Composition and antifungal activity of the essential oils of Caryocar brasiliensis. Pharmaceutical Biology, v. 41, n. 5, p. 319-324, 2003.

PAULA JUNIOR, W. Atividades biológicas in vitro de extratos hidroetanólicos de folhas e do mesocarpo interno de Caryocar brasiliense Cambess. Dissertação de Mestrado - Universidade Federal do Paraná, Setor de Ciências da Saúde, Programa de Pós-Graduação em Ciências Farmacêuticas. Defesa: Curitiba, 2004.

PELCZAR, M. J.; REID, R. D.; CHAN, E. C. S. Microbiologia. McGraw-Hill, 1981.

PEREIRA, J. V.; PEREIRA, M. S. V.; SAMPAIO, F. C.; SAMPAIO, M. C. C.; ALVES, P. M.; ARAÚJO, C. R. F.; HIGINO, J. S. Efeito antibacteriano e antiaderente in vitro do extrato da Punica granatum Linn. sobre microrganismos do biofilme dental. Revista Brasileira de Farmacognosia, v. 16, n. 1, p. 88-93, 2006.

PESSINI, G. L.; HOLETZ, F. B.; SANCHES, N. R.; CORTEZ, D. A. G.; DIAS FILHO, B. P.; NAKAMURA, C. V. Avaliação da atividade antibacteriana e antifúngica de extratos de plantas utilizados na medicina popular. Revista Brasileira de Farmacognosia, v. 13, supl. 1, p. 21-24, 2003.

PINHO, L.; SILVA SOUZA, P. N.; MACEDO SOBRINHO, E.; DE ALMEIDA, A. C.; RONIE MARTINS, E. Atividade antimicrobiana de extratos hidro alcoólicos das folhas de alecrimpimenta, aroeira, barbatimão, erva baleeira e do farelo da casca de pequi. Ciência Rural, v. 42, n. 2, p. 326-331, 2012.

POLETTO, K. Q.; REIS, C. Suscetibilidade antimicrobiana de uropatógenos em pacientes 
ambulatoriais na Cidade de Goiânia, GO. Revista da Sociedade Brasileira de Medicina Tropical, v. 38, n. 5, p. 416-420, 2005.

PUPO, M. T.; GALLO, M. B. C.; VIEIRA, P. C. Biologia química: uma estratégia moderna para a pesquisa em produtos naturais. Química Nova, v.30, n.6, p. 1446-1455, 2007.

QUINN, G. P.; KEOUGH, M. J. Experimental design and data analysis for biologists. Cambridge University Press, 2002.

RIBEIRO, R. F. Pequi, o rei do cerrado: roendo o fruto sertanejo por todos os lados. Belo Horizonte, Rede Cerrado/Rede/Caanm/Campo Vale, 2000.

ROCHA, T. J. M.; FREITAS, R. C.; AZEVEDO, R. R. D. S.; SOUZA, L. I. O.; SANTOS, A. F. Avaliação da atividade antimicrobiana e antioxidante das espécies Plectranthus amboinicus (Lour.) e Menthax villosa (Huds.). Revista de Ciências Farmacêuticas Básica e Aplicada, v. 35, n. 1, p. 113-118, 2014.

RODRIGUEZ, F. M. Evidencia y uso de plantas medicinales en los sistemas de salud. Revista Cubana de Plantas Medicinales, v. 13, n. 1, p. 0-0, 2008.

RUIZ-GARBAJOSA, P. et al. Multilocus sequence typing scheme for Enterococcus faecalis reveals hospital-adapted genetic complexes in a background of high rates of recombination. Journal of Clinical Microbiology, v. 44, n. 6, p. 2220-2228, 2006.

SANTOS, A. L.; SANTOS, D. O.; DE FREITAS, C. C.; FERREIRA, B. L. A.; AFONSO, I. F.; RODRIGUES, C. R.; CASTRO, H. C. Staphylococcus aureus: visitando uma cepa de importância hospitalar. Jornal Brasileiro de Patologia e Medicina Laboratorial, v. 43, p. 413-423, 2007.

SILVA, E. C. Microencapsulação de extrato de pequi rico em polifenóis: influência das variáveis do processo e do tipo de material de parede sobre a qualidade do produto em pó. Dissertação (Mestrado). Universidade Estadual de Campinas. Faculdade de Engenharia de Alimentos, 2013. 
SIQUEIRA, A. K.; RIBEIRO, M. G.; SALERNO, T.; TAKAHIRA, R. K.; LOPES, M. D.; PRESTES, N. C.; SILVA, A. V. Perfil de sensibilidade e multirresistência em linhagens de Escherichia coli isoladas de infecção do trato urinário, de piometra e de fezes de cães. Arquivo Brasileiro de Medicina Veterinária e Zootecnia, p. 1263-1266, 2008.

SUNDQVIST, G. Associations between microbial species in dental root canal infections. Oral Microbiology and Immunology, v. 7, n. 5, p. 257-262, 1992.

TAVARES, W. Bactérias gram-positivas problemas: resistência do estafilococo, do enterococo e do pneumococo aos antimicrobianos. Revista da Sociedade Brasileira de Medicina Tropical, v. 33, n. 3, p. 281-301, 2000.

VARANDA, E. A. Atividade mutagênica de plantas medicinais. Revista de Ciências Farmacêuticas Básica e Aplicada, v. 27, n. 1, p. 1-7, 2009.

VAZ, E. K. Resistência antimicrobiana: como surge e o que representa para a suinocultura. Acta Scientiae Veterinariae, v. 37, n. Supl 1, p. 147-150, 2009.

VEIGA JUNIOR, V. F.; PINTO, A. C.; MACIEL, M. A. M. Plantas medicinais: cura segura. Química Nova, v. 28, n. 3, p. 519-528, 2005.

VIEGAS, V.; AMARAL, L.; MATOS, C.; NASCIMENTO, O. Infecção por Staphylococcus aureus. Acta Pediátrica Portuguesa, v. 41, n. 2, p. 79-81, 2010. 